\title{
Dysregulated gene expression of extracellular matrix and adhesion molecules in saphenous vein conduits of hemodialysis patients
}

\author{
Yongxin Sun, MD, ${ }^{\mathrm{a}}$ Wenjun Ding, MD, ${ }^{\mathrm{a}}$ Qiang Wei, MD, ${ }^{\mathrm{a}}$ Zhenya Shen, $\mathrm{MD},{ }^{\mathrm{b}}$ and Chunsheng Wang, $\mathrm{MD}^{\mathrm{a}}$
}

\begin{abstract}
Objective: The incidence of cardiovascular disease was approximately 10 times higher in hemodialysis patients with end-stage renal disease than in the general population. The saphenous vein is the most commonly used conduit for coronary artery bypass grafting. However, the extracellular matrix and adhesion molecule characteristics of saphenous vein in hemodialysis patients remain unclear. The aim of the present study was to survey the extracellular matrix gene expression profile of the saphenous vein in hemodialysis patients undergoing coronary artery bypass grafting.
\end{abstract}

\begin{abstract}
Methods: A total of 34 patients undergoing elective coronary artery bypass grafting were enrolled. Of the 34 patients, 15 with end-stage renal disease required maintenance hemodialysis. The control group consisted of the other 19 patients without preoperative renal disease. Samples of the saphenous vein were obtained at coronary artery bypass grafting. The expression profile of the extracellular matrix genes was analyzed by microarray. The tissue matrix metallopeptidase/tissue inhibitor of metallopeptidase protein activities in the saphenous vein were evaluated by immunocytochemistry and Western blotting.

Results: Nineteen extracellular matrix and adhesion molecule-focused genes demonstrated at least a threefold difference in expression between the 2 groups. Upregulation was observed in 16 genes, and 3 genes appeared to be downregulated. Notable imbalanced matrix metallopeptidase/tissue inhibitor of metallopeptidase protein activities of saphenous vein exposed to end-stage renal disease conditions was found.

Conclusions: The results from present study suggest that the native extracellular matrix gene expression profile of the saphenous vein conduits in hemodialysis patients show signs of the vein graft disease process before coronary surgery. Furthermore, some preoperative profiles of hemodialysis patients undergoing coronary artery bypass grafting might provide some useful clues regarding vein graft quality and prompt adjustment in surgical strategy. (J Thorac Cardiovasc Surg 2012;144:684-9)
\end{abstract}

The incidence of cardiovascular disease is approximately 10 times greater in hemodialysis (HD) patients with end-stage renal disease (ESRD) than in the general population. ${ }^{1}$ Moreover, the cardiovascular death rates in HD patients are also greatly increased compared with those in the general population. ${ }^{2-4}$ Although percutaneous coronary intervention has made significant inroads in the revascularization of patients with coronary artery disease, some HD patients still do significantly better in terms of survival and a reduced need for additional intervention with coronary artery bypass grafting $(\mathrm{CABG}) .^{5}$ The saphenous vein $(\mathrm{SV})$ is the most commonly used CABG conduit. However, within

From the Department of Cardiac Surgery, ${ }^{\mathrm{a}}$ Zhongshan Hospital, Fudan University, Shanghai, China; and Department of Cardiac Surgery, ${ }^{\mathrm{b}}$ First Affiliated Hospital of Soochow University, Suzhou, China.

Supported by the Shanghai Medical Development Research Fund (Grant 2000I2D002).

Disclosures: Authors have nothing to disclose with regard to commercial support.

Yongxin Sun and Wenjun Ding contributed equally to this study.

Received for publication Sept 11, 2011; revisions received Nov 1, 2011; accepted for publication Dec 14, 2011; available ahead of print Jan 24, 2012.

Address for reprints: Chunsheng Wang, MD, Department of Cardiac Surgery, Zhongshan Hospital, Fudan University, 180 Fenglin Road, Shanghai 200032 China (E-mail: zswangcs@gmail.com).

$0022-5223 / \$ 36.00$

Copyright (C) 2012 by The American Association for Thoracic Surgery doi: $10.1016 /$ j.jtcvs.2011.12.037
10 years, vein graft occlusive disease occurs in nearly one half of the conduits. ${ }^{6,7}$ Vein graft failure occurs secondary to the deposition of extracellular matrix $(\mathrm{ECM}){ }^{8-10}$ However, to date, no studies have been published on the identification and understanding of the ECM and adhesion molecule characteristics of SV conduits in HD patients. The aims of the present study were, therefore, to survey the gene expression profile of the ECM and adhesion molecules in SV conduits of HD patients undergoing CABG using microarray technology.

\section{METHODS}

\section{Study Subjects}

For the present study, 34 patients with coronary artery disease undergoing elective $\mathrm{CABG}$ at our institute were enrolled. All these subjects fulfilled the inclusion criteria and agreed to participate. The local research ethics committee approved study, and each patient gave written informed consent. Of the 34 subjects, 15 with ESRD were receiving maintenance HD. The non-HD (control) group included the other 19 patients who had no preoperative history of renal disease. All patients were receiving conventional anti-angina therapy. The HD sessions were performed 3 times for $4 \mathrm{hr} / \mathrm{wk}$ using polysulphone membrane dialysers. The exclusion criteria were any inflammatory, infective disease, overt clinical heart failure, neoplastic disease, or acute coronary event during the previous 2 months. The patients previously diagnosed with diabetes mellitus (fasting glucose $>5.5 \mathrm{mmol} / \mathrm{L}$ ), hyperlipidemia (total cholesterol level $>5.2 \mathrm{mmol} / \mathrm{L}$ ), or hypertension (systolic blood pressure $>140 \mathrm{~mm} \mathrm{Hg}$, diastolic blood 

Abbreviations and Acronyms
$\mathrm{ECM}=$ extracellular matrix
$\mathrm{ESRD}=$ end-stage renal disease
$\mathrm{CABG}=$ coronary artery bypass grafting
$\mathrm{HD}=$ hemodialysis
$\mathrm{SV}=$ saphenous vein

pressure $>90 \mathrm{~mm} \mathrm{Hg}$ ) were receiving appropriate glucose, lipid-lowering, or hypertension treatment. The individual characteristics of the patients are listed in Table 1.

\section{Tissue Samples and RNA Extraction}

Samples of the SV were obtained at CABG. Segments of a few millimeters from the SV were isolated and immediately put into RNAlater ${ }^{\mathrm{TM}}$ (Ambion, Austin, Tex) for storage at $-80^{\circ} \mathrm{C}$. Total RNA extraction was performed using the RNeasy Mini kit (Qiagen, Valencia, Calif) according to the manufacturer's instructions. Next, 1 to $2.0 \mu \mathrm{g}$ of total RNA was reverse transcribed into single strand cDNA using MuLV reverse transcriptase (Applied Biosystems, Foster City, Calif).

\section{cDNA Gene Expression Array Analysis}

The expression profile of extracellular matrix and adhesion molecules genes was analyzed using the $\mathrm{RT}^{2}$ Profiler ${ }^{\mathrm{TM}}$ PCR Array Human Extracellular Matrix and Adhesion Molecules (PAHS-013A; SuperArray Bioscience, Frederick, Md). The results were analyzed using ScanAlyze and GEArray Analyzer (SuperArray Bioscience).

\section{Immunocytochemistry Evaluation of MMP-2, MMP-9, TIMP-2, and TIMP-3 Activity in SV of HD and Control Groups}

The optimal dilutions for each primary antibody (Santa Cruz Biotechnology, Santa Cruz, Calif) were found. The sections were incubated with goat anti-mouse biotinylated second antibody IgGs (Beijing Zhongshan, Beijing, China). Semiquantitative evaluation was performed by computer-assisted image analysis (Chengdu Taimeng, Sichuan, China).

\section{Western Blot Analysis of Tissue MMP-2, MMP-9, TIMP-2, and TIMP-3 Levels}

Total protein was fractionated and transferred to polyvinylidene difluoride membranes (Millipore, Bedford, Mass). Each membrane was incubated with specific antibodies (Calbiochem, San Diego, Calif) with secondary antibody (Jackson Immunolab, West Grove, Pa). Immune complexes were visualized with the enhanced chemiluminescence detection system (Amersham, Piscataway, NJ).

\section{Statistical Analysis}

All values are expressed as the mean \pm standard deviation. Quantitative reverse transcriptase-polymerase chain reaction results are reported as the relative gene expression, and the $\mathrm{x}$-fold change in target genes was determined using the $2-\Delta \Delta \mathrm{C}_{\mathrm{t}}$ method, as previously described. ${ }^{11}$ To evaluate the gene expression profile in the HD group, the $\mathrm{x}$-fold change was determined as $\left(\mathrm{C}_{\mathrm{tHD}}-\mathrm{C}_{\mathrm{t} \text { Actin }}\right)-\left(\mathrm{C}_{\mathrm{t} \text { Control }}-\mathrm{C}_{\mathrm{t}}\right.$ Actin $)$. The group comparisons were performed using the Student $t$ test. Univariate and multivariate linear regression analyses (Cox regression model) were performed to analyze the extent of matrix metallopeptidase-2/tissue inhibitor of metallopeptidase-2 (MMP-2/TIMP-2) imbalance in relation to the preoperative variables.
TABLE 1. Demographics of studied population

\begin{tabular}{lccr}
\hline \multicolumn{1}{c}{ Demographic } & $\begin{array}{c}\text { HD group } \\
(\mathbf{n}=\mathbf{1 5})\end{array}$ & $\begin{array}{c}\text { Control group } \\
(\mathbf{n}=\mathbf{1 9})\end{array}$ & $\begin{array}{c}\boldsymbol{P} \\
\text { value }\end{array}$ \\
\hline Gender (male) & $11(73.3 \%)$ & $15(78.9 \%)$ & .39 \\
Age (yr) & $62.6 \pm 10.3$ & $60.1 \pm 15.5$ & .44 \\
Body weight (kg) & $66.2 \pm 10.6$ & $68.5 \pm 13.7$ & .41 \\
History of smoking (n) & $6(40.0 \%)$ & $8(42.1 \%)$ & .38 \\
History of MI (n) & $4(26.7 \%)$ & $4(21.1 \%)$ & .23 \\
Previous PCI (n) & $9(60.0 \%)$ & $11(57.9 \%)$ & .29 \\
Hypertension (n) & $8(53.3 \%)$ & $8(42.1 \%)$ & .12 \\
Diabetic mellitus (n) & $5(33.3 \%)$ & $6(31.5 \%)$ & .34 \\
Cerebral vessel disease (n) & $5(33.3 \%)$ & $4(21.1 \%)$ & .07 \\
Peripheral vascular disease (n) & $5(33.3 \%)$ & $4(21.1 \%)$ & .09 \\
Duration of HD (yr) & $2.2 \pm 0.9$ & & \\
Total cholesterol & $5.80 \pm 2.25$ & $5.04 \pm 1.46$ & .14 \\
$\quad$ level (mmol/L) & & & \\
Lipoprotein(a) (mg/L) & $721.0 \pm 253.6$ & $267.3 \pm 119.8$ & $<.01$ \\
Apolipoprotein A (g/L) & $2.48 \pm 1.13$ & $1.39 \pm 0.84$ & .04 \\
Apolipoprotein B (g/L) & $3.09 \pm 1.54$ & $1.67 \pm 0.92$ & $<.01$ \\
Calcium concentration & $2.64 \pm 1.31$ & $2.25 \pm 0.77$ & .20 \\
$\quad$ (mmol/L) & & & \\
Phosphorus concentration & $2.77 \pm 0.86$ & $1.05 \pm 0.24$ & $<.01$ \\
$\quad$ (mmol/L) & & & \\
Calcium $\times$ phosphorus product & $55.74 \pm 13.08$ & $35.16 \pm 4.31$ & $<.01$ \\
PTH (ng/L) & $509.6 \pm 313.6$ & $80.5 \pm 44.7$ & $<.01$ \\
Homocysteine (mmol/L) & $37.6 \pm 10.9$ & $18.8 \pm 6.5$ & .02 \\
IMT in carotid arteries (mm) & $1.46 \pm 0.32$ & $0.90 \pm 0.14$ & $<.01$ \\
Coronary artery calcification & $695.0 \pm 126.8$ & $507.3 \pm 88.2$ & .03 \\
$\quad$ score & & & \\
\hline & & & \\
\hline
\end{tabular}

$\overline{H D \text {, Hemodialysis; } M I \text {, myocardial infarction; } P C I \text {, percutaneous coronary interven- }}$ tion; $P T H$, parathyroid hormone; $I M T$, intima-media thickness.

\section{RESULTS}

\section{Demographic Patient Characteristics}

The demographics of the population studied did not differ between the HD and control groups, except for the parameters related to ESRD. The 2 groups were well matched for age, gender, and presentation profile (Table 1).

\section{Dysregulated Expression of Gene Profiles}

Using the RT ${ }^{2}$ Profiler ${ }^{\mathrm{TM}}$ PCR Array Human Extracellular Matrix and Adhesion Molecules (SuperArray Bioscience), we examined the gene expression profile and compared the relative expression of ECM and adhesion molecule genes in SV between the HD and control groups. Of the 84 ECM and adhesion molecule-focused genes in this microarray, 19 genes demonstrated at least a threefold difference in expression between the HD and control groups. Upregulation was observed in 16 genes, and 3 genes appeared to be downregulated (Table 2). The extent of MMP-2/TIMP-2 imbalance was calculated with the $x$-fold changes of the genes. The extent of MMP-2/TIMP-2 imbalance of the SV in the HD group appeared significantly increased compared with the normal control veins $(4.57 \pm$ 1.24 vs $0.84 \pm 0.29, P<.05)$. Univariate and multivariate 
TABLE 2. ECM-related genes regulated in saphenous vein of hemodialysis patients compared with control group*

\begin{tabular}{llcr}
\hline Symbol & \multicolumn{1}{c}{ Description } & $\begin{array}{c}\text { x-Fold } \\
\text { difference }\end{array}$ & $\begin{array}{c}\boldsymbol{P} \\
\text { value }\end{array}$ \\
\hline CDH1 & Cadherin 1, type 1, E-cadherin & $23.83 \pm 11.09$ & $<.001$ \\
COL12A1 & Collagen, type XII, alpha 1 & $6.74 \pm 2.25$ & .003 \\
COL16A1 & Collagen, type XVI, alpha 1 & $5.61 \pm 2.06$ & .005 \\
COL1A1 & Collagen, type I, alpha 1 & $3.29 \pm 1.44$ & .011 \\
ITGA3 & Integrin, alpha 3 & $4.15 \pm 1.63$ & .008 \\
MMP1 & Matrix metallopeptidase 1 & $8.15 \pm 3.80$ & .001 \\
MMP2 & Matrix metallopeptidase 2 & $19.93 \pm 11.75$ & $<.001$ \\
MMP12 & Matrix metallopeptidase 12 & $13.00 \pm 13.55$ & $<.001$ \\
MMP13 & Matrix metallopeptidase 13 & $6.76 \pm 2.59$ & .003 \\
MMP3 & Matrix metallopeptidase 3 & $10.85 \pm 9.06$ & $<.001$ \\
MMP7 & Matrix metallopeptidase 7 & $15.51 \pm 38.62$ & $<.001$ \\
MMP8 & Matrix metallopeptidase 8 & $17.91 \pm 30.58$ & $<.001$ \\
MMP9 & Matrix metallopeptidase 9 & $19.36 \pm 5.50$ & $<.001$ \\
SGCE & Sarcoglycan, epsilon & $28.91 \pm 13.40$ & $<.001$ \\
THBS1 & Thrombospondin 1 & $15.30 \pm 6.93$ & $<.001$ \\
TIMP1 & Tissue metallopeptidase inhibitor 1 & $-4.60 \pm 0.58$ & .007 \\
TIMP2 & Tissue metallopeptidase inhibitor 2 & $-3.58 \pm 0.96$ & .009 \\
TIMP3 & Tissue metallopeptidase inhibitor 3 & $-11.30 \pm 4.38$ & $<.001$ \\
TNC & Tenascin C & $7.81 \pm 2.01$ & .002 \\
\hline x Fol & &
\end{tabular}

$\mathrm{x}$-Fold change for each gene from HD group to control group calculated as $2^{-\Delta \Delta \mathrm{Ct}}$ Among 84 genes analyzed, 16 genes were upregulated $>3$.0-fold, and 3 were downregulated in SV conduits of HD patients. $E C M$, Extracellular membrane; $H D$, hemodialysis; $S V$, saphenous vein. *Gene expression changes $\geq 3$.0-fold versus control in RNA level.

linear regression analyses showed that the extent of MMP2/TIMP-2 imbalance of the SV was directly related to some preoperative ESRD-related parameters (Tables 3 and 4).

\section{Changed Activities of MMP-2, MMP-9, TIMP-2 and TIMP-3 in SV of HD Group}

A semiquantitative analysis showed that the MMP-2 and MMP-9 levels in the SV of the HD group (grade, $2.6 \pm 0.5$ and $1.8 \pm 0.4$, respectively) were significantly greater than those in the normal SV (grade, $0.7 \pm 0.16$ and $0.6 \pm 0.15$; $P<.01$ and $P<.02$, respectively). TIMP-2 and TIMP-3 immunostaining were notably reduced in the SV of the HD group compared with those in the control group (grade, $0.6 \pm 0.19$ vs $2.2 \pm 0.3$ and $0.9 \pm 0.28$ vs $2.4 \pm 0.7$; $P<.05$ and $P<.05$, respectively). Figure 1 shows the results of the immunocytochemistry evaluation.

\section{Alteration of Tissue MMP-2, MMP-9, TIMP-2 and TIMP-3 Protein Levels Induced by ESRD}

The SV exposed to ESRD conditions demonstrated a notable increase in MMP-2 and MMP-9 protein levels compared with the normal SV $(1.48 \pm 0.33$ vs $0.92 \pm 0.16$ densitometry unit and $1.72 \pm 0.49$ vs $0.98 \pm 0.22$ densitometry unit, $P<.05$ and $P<.05$, respectively). In contrast, the TIMP-2 and TIMP-3 protein levels in the SV of the HD group were significantly decreased compared with that in the normal control veins $(66.3 \pm 15.8$ vs $119.4 \pm 20.1$
TABLE 3. Univariate linear regression analysis of ESRD-related parameters in relation to MMP-2/TIMP-2 imbalance of SV conduits

\begin{tabular}{llcc}
\hline \multicolumn{1}{c}{ Variable } & $\begin{array}{c}\text { Odds } \\
\text { ratio }\end{array}$ & $\begin{array}{c}\mathbf{9 5} \% \text { Confidence } \\
\text { interval }\end{array}$ & $\begin{array}{c}\boldsymbol{P} \\
\text { value }\end{array}$ \\
\hline Gender (male vs female) & 1.247 & $0.48-2.6$ & .93 \\
Age & 1.004 & $0.97-1.09$ & .81 \\
Body weight & 1.005 & $0.96-1.04$ & .08 \\
Hypertension & 0.69 & $0.073-2.88$ & .26 \\
Hyperlipidemia & 0.55 & $0.084-2.51$ & .89 \\
Cerebral vessel disease & 1.83 & $0.042-2.05$ & .10 \\
Periphery vessel disease & 1.66 & $0.105-2.79$ & .14 \\
Diabetic mellitus & 1.902 & $0.73-3.68$ & .09 \\
Total cholesterol level & 1.57 & $0.048-2.39$ & .10 \\
Lipoprotein(a) & 3.19 & $1.92-4.08$ & .03 \\
Apolipoprotein A & 1.17 & $0.54-1.85$ & .15 \\
Apolipoprotein B & 4.48 & $1.77-15.49$ & .02 \\
Calcium concentration & 0.66 & $0.19-1.31$ & .17 \\
Phosphorus concentration & 0.42 & $0.051-1.65$ & .11 \\
Calcium $\times$ phosphorus product & 0.93 & $0.063-1.82$ & .14 \\
PTH & 0.55 & $0.041-1.07$ & .19 \\
Homocysteine & 1.038 & $0.96-1.54$ & .08 \\
IMT in carotid arteries & 7.05 & $2.041-8.07$ & .01 \\
Coronary artery calcification score & 6.49 & $1.56-7.13$ & .04 \\
\hline$E S D D$ E
\end{tabular}

ESRD, End-stage renal disease; $M M P$, matrix metallopeptidase; TIMP, tissue metallopeptidase inhibitor; $S V$, saphenous vein; $P T H$, parathyroid hormone; $I M T$, intimamedia thickness.

densitometry unit and $73.7 \pm 11.6$ vs $98.5 \pm 18.2$ densitometry unit, $P<.05$ and $P<.05$, respectively). Figure 2 displays the results from the Western blotting analysis.

\section{DISCUSSION}

It is well known that the arterial alterations induced by ESRD include changes in arterial wall thickness due to rearrangements of the cellular elements and ECM of the vessel wall. ${ }^{12,13}$ Although arterial conduit use has become the standard procedure for CABG, with the concern of the limited life expectancy of the HD patient with severe coronary artery disease, the complications of dialysis, including osteoporosis and coagulation dysfunction, flow steal during hemodialysis with upper extremity arteriovenous fistula, and the patients' poor native coronary artery conditions, we did not use the left internal mammary artery conduits as much as we expected during clinical practice. ${ }^{14} \mathrm{SV}$ conduits can be the more reliable and available conduits in these cases. The cardiovascular

TABLE 4. Multivariate linear regression analysis of ESRD-related parameters in relation to MMP-2/TIMP-2 imbalance of SV conduits

\begin{tabular}{lrcr}
\hline \multicolumn{1}{c}{ Variable } & $\begin{array}{c}\text { Odds } \\
\text { ratio }\end{array}$ & $\begin{array}{c}\mathbf{9 5} \% \text { Confidence } \\
\text { interval }\end{array}$ & $\begin{array}{c}\boldsymbol{P} \\
\text { value }\end{array}$ \\
\hline IMT in carotid arteries & 16.43 & $2.02-18.37$ & $<.01$ \\
Coronary artery calcification score & 5.57 & $1.32-7.59$ & .01 \\
\hline
\end{tabular}

$E S R D$, End-stage renal disease; $M M P$, matrix metallopeptidase; $S V$, saphenous vein; $I M T$, intima-media thickness. 

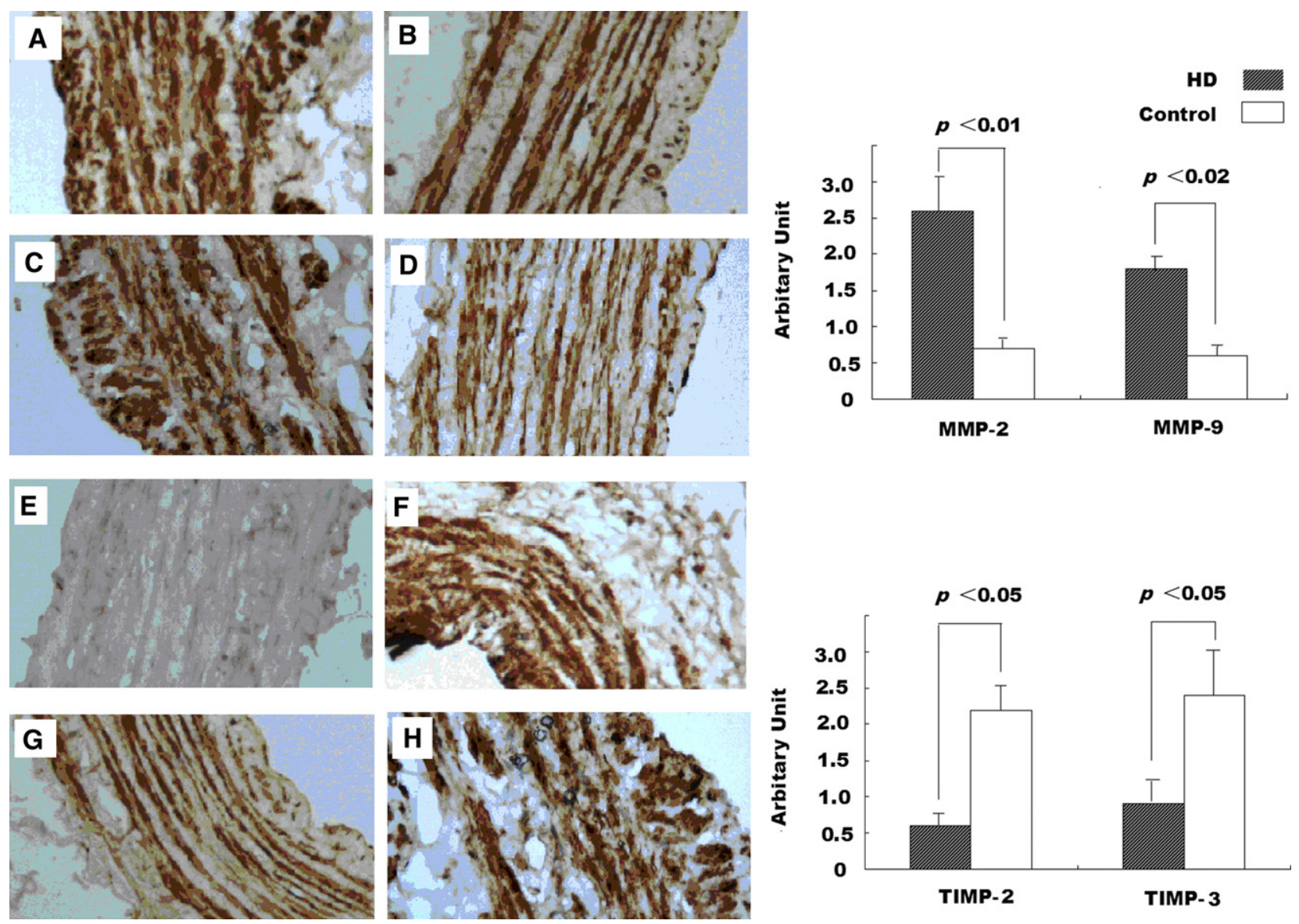

FIGURE 1. Immunohistochemical evaluation of matrix metallopeptidase (MMP)-2, MMP-9, tissue inhibitor of metallopeptidase (TIMP)-2, and TIMP-3 activity in saphaneous vein $(S V)$ of hemodialysis $(H D)$ and control groups (A-H, DAB staining, original magnification $\times 100)$. SV of HD group $(\mathrm{n}=15)$ showed high expression of MMP-2 and MMP-9 (A and C, respectively). In contrast, in control group ( $\mathrm{n}=19$ ), their expression was low (B and D); TIMP-2 and TIMP-3 immunostaining were notably reduced in SV of HD group (E and G, respectively) compared with those in control group (F and H, respectively).

damage in HD patients includes a variety of changes in the vessels. ${ }^{15,16}$ The vascular changes involve both cellular and extracellular components. The ECM is a dynamic structure that requires constant synthesis and degradation by MMPs. This is tightly controlled by the TIMPs. Therefore, increased ECM protein synthesis, increased MMP activity, and decreased TIMP activity might contribute to vascular ECM deposition and fibrosis. ECM displays a very dynamic equilibrium in which there is constant synthesis, degradation, and reorganization. ${ }^{17}$ Our results revealed the ECM and adhesion molecule characteristics in the SV conduits of HD patients. Before being exposed to the increased blood flow and pressure in the arterial system, the pathologic remodeling of the SV, characterized by ECM deposition, in HD patients has begun. Furthermore, the Cox linear regression analysis showed the relationship between the extent of MMP-2/TIMP-2 imbalance and some important preoperative variables. Therefore, if the SV quality revealed by the preoperative profile was poor, the surgical strategy should be adjusted, and more arterial conduits should be used, although some limitations and concerns exist about the use of arterial conduits for CABG in $\mathrm{HD}$ patients.

To determine how the activity of the ECM and adhesion molecules is altered in SV of HD patients, the gene expression profile was investigated using microarray analysis. Our data indicate that some risk factors induced by ESRD in HD patients deeply influence the biologic properties of ECM activity in SV conduits. The ECM and adhesion molecule gene expression profile of the SV conduits in HD patients showed signs of the vein graft disease process before coronary surgery. Some important ECM and adhesion molecules genes, including the MMP/TIMP system and collagen, showed significantly different activity.

In addition to the increased traditional risk factors, HD patients could also have a number of nontraditional cardiovascular risk factors that might play an important role in the pathogenesis of vein graft disease. ${ }^{18,19}$ Also, the pathogenesis of cardiovascular damage in HD patients is far more complex than in the general population. Moreover, this increase in 


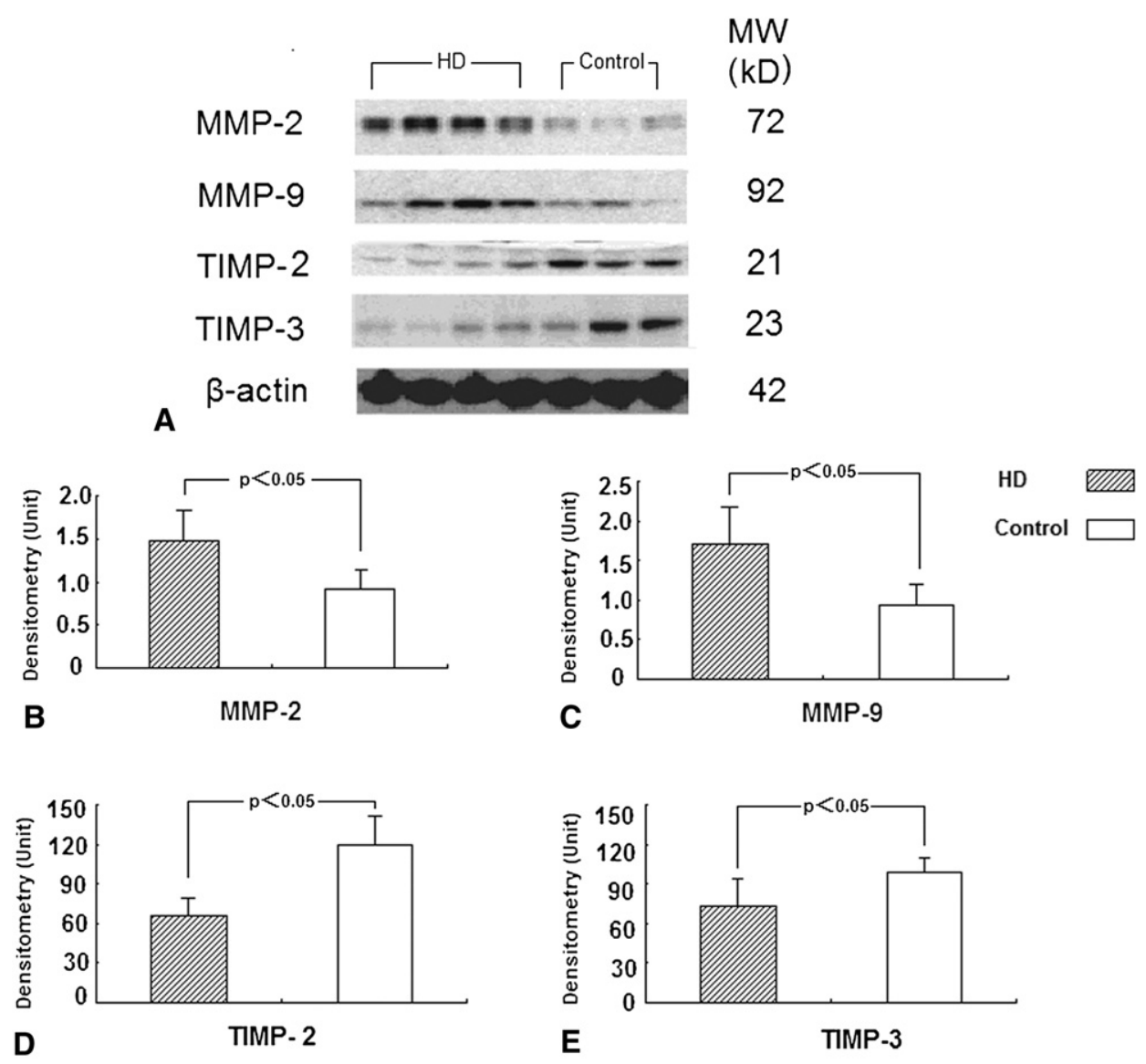

FIGURE 2. Alteration of saphaneous vein ( $S V$ ) tissue matrix metallopeptidase (MMP)-2, MMP-9, metallopeptidase (TIMP)-2 and TIMP-3 protein levels induced by end-stage renal disease (ESRD). A, Representative Western blot showing tissue MMP-2, MMP-9, TIMP-2, and TIMP-3 expression in SV samples of hemodialysis $(H D)$ and control groups. $\beta$-Actin was the loading control. B, Densitometric evaluation of MMP-2 expression; C, MMP-9; D, TIMP-2; and E, TIMP-3.

the risk of coronary heart disease is not entirely explained by the traditional risk factors for cardiovascular disease. The complex effect of some nontraditional risk factors, including lipoprotein(a), apolipoprotein A, apolipoprotein $\mathrm{B}$, homocysteine, calcium, phosphorus, and parathyroid hormone, on SV conduits of HD patients is not well known. Our findings also suggest that the extent of MMP-2/TIMP-2 imbalance of SV was directly related to some preoperative ESRD-related parameters.

The atherosclerotic changes in the carotid arteries measured by ultrasonography mirror the atherosclerosis of the coronary arteries in the general population and in HD patients. ${ }^{20,21}$ In some studies, a significant increase was found in the intima-media thickness and plaque occurrence in the carotid arteries in the HD patients compared with the age- and gender-matched healthy control subjects. ${ }^{22}$ In the present study, a positive correlation between intima-media thickness and plaque occurrence plaques in the carotid arteries with the extent of MMP-2/TIMP-2 imbalance in the SV conduits in HD patients was also observed. Therefore, intima-media thickness and plaque occurrence plaques in carotid arteries could be considered a mirror of the SV condition in HD patients. Because coronary artery calcification score is a sensitive marker of coronary artery atherosclerosis, it would be of interest to determine whether it has a direct relationship with the MMP-2/TIMP-2 imbalance of the SV in HD patients. ${ }^{23}$ Our data have shown that coronary artery calcification score can be viewed as a sign of SV remodeling in HD patients. It was observed that increased lipoprotein(a) and apolipoprotein B levels had significant correlation with carotid atherosclerosis in HD patients. Such a significant correlation was also found when SV remodeling was considered. Although high apolipoprotein A, homocysteine, calcium, phosphorus, and parathyroid hormone levels have been independently associated with greater rates of cardiovascular disease in patients with ESRD, the data did not show a direct correlation between them and SV conduit damage in the HD patients in our study. The explanation for such unexpected results might be related to the limited number of patients. Nevertheless, these findings have demonstrated the importance of careful monitoring and management for some nontraditional risk 
factors in patients with ESRD, particularly if they have undergone CABG. Therefore, the assessment of some nontraditional risk factors in HD patients scheduled to undergo CABG might offer useful information on conditions of grafting conduits for coronary surgery.

In conclusion, the results from our study suggest that the ECM and adhesion molecule gene expression profile of the SV conduits in HD patients has shown signs of the vein graft disease process before coronary surgery. Some important ECM and adhesion molecule genes showed significantly different activity that was induced by ESRD. Moreover, these observations raise the question of whether a local genetic anticoagulant treatment should be considered for HD patients with vein bypass grafts. Novel therapeutic approaches could develop that transform the SV conduit into a vessel with increased long-term patency. ${ }^{24}$ This question, however, remains to be answered by appropriately designed clinical trials.

\section{Study Limitations}

Several limitations of the present study have to be addressed. First, the study focused on the native pathologic remodeling of the SV in HD patients. However, surgical manipulation could affect SV graft integrity and might promote neointima characterized by ECM deposition, which need to be investigated. Second, although there were significantly different ECM and adhesion molecule gene activities between the HD and normal SV conduits, the numbers of specimens was still too small to reach the definitive conclusion. Third, although the microarray demonstrated the expression files of 84 ECM and adhesion molecule-focused genes, techniques with greater sensitivity and more detailed profiles to investigate the pathologic remodeling of SV characterized by the ECM deposition still need to be found.

\section{References}

1. Foley RN, Parfrey PS, Sarnak MJ. Clinical epidemiology of cardiovascular disease in chronic renal disease. Am J Kidney Dis. 1998;32:S112-9.

2. Wolfe RA, Ashby VB, Milford EL, Ojo AO, Ettenger RE, Agodoa LY, et al. Comparison of mortality in all patients on dialysis, patients on dialysis awaiting transplantation, and recipients of a first cadaveric transplant. N Engl J Med. 1999; 341:1725-30

3. Go AS, Chertow GM, Fan D, McCulloch CE, Hsu CY. Chronic kidney disease and the risks of death, cardiovascular events, and hospitalization. $N$ Engl $J$ Med. 2004;351:1296-305.

4. Stack AG, Bloembergen WE. Prevalence and clinical correlates of coronary artery disease among new dialysis patients in the United States: a cross-sectional study. J Am Soc Nephrol. 2001;12:1516-23.

5. Sunagawa G, Komiya T, Tamura N, Sakaguchi G, Kobayashi T, Murashita T. Coronary artery bypass surgery is superior to percutaneous coronary intervention with drug-eluting stents for patients with chronic renal failure on hemodialysis. Ann Thorac Surg. 2010;89:1896-900.
6. Goldman S, Zadina K, Moritz T, Ovitt T, Sethi G, Copeland JG, et al., VA Cooperative Study Group \#207/297/364. Long-term patency of saphenous vein and left internal mammary artery grafts after coronary artery bypass surgery: results from a Department of Veterans Affairs Cooperative Study. J Am Coll Cardiol. 2004;44:2149-56.

7. Schwartz L, Kip KE, Frye RL, Alderman EL, Schaff HV, Detre KM, Bypass Angioplasty Revascularization Investigation. Coronary bypass graft patency in patients with diabetes in the Bypass Angioplasty Revascularization Investigation (BARI). Circulation. 2002;106:2652-8.

8. Anstadt MP, Franga DL, Portik-Dobos V, Pennathur A, Bannan M, Mawulawde K, et al. Native matrix metalloproteinase characteristics may influence early stenosis of venous versus arterial coronary artery bypass grafting conduits. Chest. 2004;125:1853-8.

9. Turner NA, Ho S, Warburton P, O'Regan DJ, Porter KE. Smooth muscle cells cultured from human saphenous vein exhibit increased proliferation, invasion, and mitogen-activated protein kinase activation in vitro compared with paired internal mammary artery cells. J Vasc Surg. 2007;45:1022-8.

10. Jia G, Mitra AK, Gangahar DM, Agrawal DK. Insulin-like growth factor-1 induces phosphorylation of PI3K-Akt/PKB to potentiate proliferation of smooth muscle cells in human saphenous vein. Exp Mol Pathol. 2010;89:20-6.

11. Song W, Ergul A. Type-2 diabetes-induced changes in vascular extracellular matrix gene expression: relation to vessel size. Cardiovasc Diabetol. 2006;5:3.

12. Turunen P, Puhakka H, Rutanen J, Hiltunen M, Heikura T, Gruchala M, YlaHerttuala S. Intravascular adenovirus-mediated lipoprotein-associated phospholipase A2 gene transfer reduces neointima formation in balloon-denuded rabbit aorta. Atherosclerosis. 2005;179:27-33.

13. Boot MJ, Steegers-Theunissen RP, Poelmann RE, Iperen L, Gittenberger-de Groot AC. Homocysteine induces endothelial cell detachment and vessel wall thickening during chick embryonic development. Circ Res. 2004;94:542-9.

14. Gaudino M, Serricchio M, Luciani N, Giungi S, Salica A, Pola R, et al. Risks of using internal thoracic artery grafts in patients in chronic hemodialysis via upper extremity arteriovenous fistula. Circulation. 2003;107:2653-5.

15. Guérin AP, London GM, Marchais SJ, Metivier F. Arterial stiffening and vascular calcifications in end-stage renal disease. Nephrol Dial Transplant. 2000;15: 1014-421

16. Chung AW, Yang HH, Kim JM, Sigrist MK, Chum E, Gourlay WA, et al. Upregulation of matrix metalloproteinase- 2 in the arterial vasculature contributes to stiffening and vasomotor dysfunction in patients with chronic kidney disease. Circulation. 2009;120:792-801.

17. Fernández-Hernando C, József L, Jenkins D, Di Lorenzo A, Sessa WC. Absence of Akt1 reduces vascular smooth muscle cell migration and survival and induces features of plaque vulnerability and cardiac dysfunction during atherosclerosis. Arterioscler Thromb Vasc Biol. 2009;29:2033-40.

18. Galis ZS, Johnson C, Godin D, Magid R, Shipley JM, Senior RM, et al. Targeted disruption of the matrix metalloproteinase-9 gene impairs smooth muscle cell migration and geometrical arterial remodeling. Circ Res. 2002;91:852-9.

19. Galis ZS, Khatri JJ. Matrix metalloproteinases in vascular remodeling and atherogenesis: the good, the bad, and the ugly. Circ Res. 2002;90:251-62.

20. Papagianni A, Dovas S, Bantis C, Belechri AM, Kalovoulos M, Dimitriadis C, et al. Carotid atherosclerosis and endothelial cell adhesion molecules as predictors of long-term outcome in chronic hemodialysis patients. Am J Nephrol. 2008; 28:265-74.

21. Pawlak K, Pawlak D, Mysliwiec M. Serum matrix metalloproteinase-2 and increased oxidative stress are associated with carotid atherosclerosis in hemodialyzed patients. Atherosclerosis. 2007;190:199-204.

22. Delucchi A, Dinamarca H, Gainza H, Whitttle C, Torrealba I, Iñiguez G. Carotid intima-media thickness as a cardiovascular risk marker in pediatric end-stage renal disease patients on dialysis and in renal transplantation. Transplant Proc. 2008;40:3244-6.

23. Ohtake T, Ishioka K, Honda K, Oka M, Maesato K, Mano T, et al. Impact of coronary artery calcification in hemodialysis patients: risk factors and associations with prognosis. Hemodial Int. 2010;14:218-25.

24. Akowuah EF, Gray C, Lawrie A, Sheridan PJ, Su CH, Bettinger T, et al. Ultrasound-mediated delivery of TIMP-3 plasmid DNA into saphenous vein leads to increased lumen size in a porcine interposition graft model. Gene Ther. 2005;12:1154-7. 